\title{
Tendências da distribuição da população urbana e dos serviços básicos no Brasil: 1980- 2000. Distinções com Argentina e México.
}

\author{
Sueli Ramos Schiffer ${ }^{1}$
}

\begin{abstract}
Resumo
Analisa-se a evolução do crescimento demográfico e a distribuição espacial da população brasileira entre 1980 e 2000, estabelecendo-se distinções com os processos demográficos ocorridos no México e Argentina em igual período. Destacam-se as diferenciações quanto aos índices de concentração da população urbana desses países em suas maiores cidades.

O padrão de crescimento populacional, nos países mencionados, é avaliado considerando-se a segmentação por faixa etária, em particular quanto à evolução da população acima de 65 anos e a entre 0 e 14 anos. Adicionalmente, confrontam-se as tendências demográficas observadas com os respectivos indicadores nacionais macroeconômicos, de distribuição de renda, do valor adicionado por setor de atividade e das taxas de desemprego.

Para o caso brasileiro, discutem-se as relações entre o número médio de pessoas nas famílias e os percentuais de atendimento dos serviços públicos básicos, por classes de renda familiar segundo as Grandes Regiões e as regiões metropolitanas, em 1998.
\end{abstract}

Palavras-Chave: Brasil - demografia; Brasil - Argentina - México - evolução demográfica; Brasil - Argentina México - distribuição espacial da população; Brasil - serviços públicos básicos; Brasil - Argentina - México indicadores macroeconômicos.

\begin{abstract}
The trends of the demography growth and the geographical distribution of the Brazilian population from 1980 to 2000 are assessed, at the same time specifying the distinctions from the Mexican and Argentinean demographic processes. It is emphasized the differences concerning the share of the urban population living in the biggest cities of each of these countries.

The specific pattern of the population growth rate in the mentioned countries is evaluated based on age groups, particularly the share of the more aged one (over 65 years) and of the children between 0 and 14 years old. Additionally, the demographic recent trends observed are confronted to the respective national indicators such as economic growth rate, income distribution, value added by economic sector and unemployment rate.

Focusing in the Brazilian case in 1998, the relations between the share of families by income groups are discussed regarding the average number of family members and the percent of households connected to sewage, water and garbage public services, according to the national regions and to the metropolitan areas.
\end{abstract}

Key words: Brazil - demography; Brazil - Argentina - Mexico - demographic growth; Brazil - Argentina - Mexico geographical distribution of the population ; Brazil - household public services; Brazil - Argentina - Mexico macroeconomic data.

1 Professora Titular da Faculdade de Arquitetura e Urbanismo da Universidade de São Paulo e chefe do Departamento de Tecnologia - FAU/USP; Linhas de Pesquisa: planejamento urbano e regional; e-mail: srschif@usp.br. 


\section{Introdução}

As tendências recentes do processo demográfico e as perspectivas econômicas no Brasil serão tratadas nesse texto visando sinalizar as implicações quanto ao mercado de trabalho urbano, tema central dos demais textos desta pesquisa. Os dados analisados originam-se essencialmente da Sinopse Preliminar do Censo Demográfico de 2000 e na Síntese de Indicadores Sociais 2000, extraídos da Pesquisa Nacional por Amostra de Domicílios - PNAD - de 1992 e 1999, ambos realizados pela Fundação Instituto Brasileiro de Geografia e Estatística - FIBGE.

O que se observa neste início do século XXI no Brasil é a continuidade da tendência das últimas décadas de menor crescimento populacional associado à consolidação do processo de urbanização em praticamente todas as grandes regiões do país. As principais cidades brasileiras, e latino-americanas, tem ainda apresentado crescente aumento da taxa de envelhecimento da população. A distribuição dos serviços públicos urbanos não tem apresentado evolução capaz de suprir as carências de infra-estrutura básica, como habitação, educação e saneamento, em especial no que se refere à população de baixa renda.

Os indicadores macroeconômicos brasileiros sinalizam para os próximos anos menores taxas de crescimento econômico, além de tendências crescentes do predomínio do setor terciário, do aumento do emprego informal e das taxas de desemprego, e nenhuma alteração significativa na distribuição interpessoal de renda. Neste cenário demográfico e econômico é que se devem inserir as projeções sobre o mercado de trabalho.

Compara-se, a título de referência e de forma sucinta, as tendências brasileiras com as da Argentina e do México, tomando-se como base os indicadores sócio-econômicos elaborados anualmente pelo Banco Mundial. 


\section{O processo demográfico recente}

Os dados preliminares do censo demográfico brasileiro realizado no ano 2000 (FIBGE, 2001a) indicam que na década de 1990 manteve-se a tendência de declínio do crescimento populacional. A taxa média geométrica de crescimento da população total durante os anos 90 foi de $1,63 \%$ ao ano, confirmando uma redução que se processa desde a década de 1950, quando atingiu 2,99\% ao ano, mas em ritmo menos acentuado, se comparado à respectiva taxa da década imediatamente anterior, de $1,93 \%$ ao ano.

As Regiões Norte e Centro-Oeste apresentaram as maiores taxas de crescimento populacional na década de 1990, enquanto a Região Nordeste foi responsável pela menor taxa (Tabela 1). Estas tendências são explicadas como resultado do processo migratório que privilegia as duas primeiras regiões como áreas de atração populacional, enquanto que a última se mantém como a região de maior emigração do território brasileiro, dada as dificuldades históricas relacionadas ao fraco mercado de trabalho local como resultado de terras pouco produtivas e com acentuados períodos de seca em grande parte do Nordeste (região do sertão).

O processo migratório no Brasil, dimensionado na PNAD 1999 (FIBGE, 2001) indica que naquele ano aproximadamente 15,5 milhões de pessoas residiam fora de suas regiões de nascimento, o que representava em torno de 9,5\% da população total. A mesma PNAD informa ainda que entre 1992 e 1999 "as proporções de emigrantes segundo a região de naturalidade não sofreram mudanças significativas. Deste contingente, o Nordeste é, ainda, a região que, com maior intensidade, continua a expulsar sua população (cerca de 55\% dos emigrantes são nordestinos, [... sendo] que a Região Sudeste continuou a ser o principal local de destino dos emigrantes", tendo recebido 53,6\% do total de migrantes nacionais (FIBGE, 2001: 23).

A taxa de fecundidade total medida pelo número médio de filhos por mulher em idade reprodutiva, segundo dados da PNAD 1999, tem decrescido ainda mais significativamente: de 5,8 filhos em 1970, para 2,3 em 1999. "Refletindo o ritmo da queda da fecundidade, o tamanho das famílias vem sofrendo nas últimas décadas contínuas reduções, sendo que, em 1980, o número médio de pessoas era de 4,5. Em 1992, este número já caía para 3,7 para, posteriormente, em 
1999, atingir apenas 3,4 pessoas em média”. (FIBGE, 2001: 203). Processo este decorrente do fim do estágio de urbanização, já que a população urbana tende a ter menos filhos face às dificuldades relacionadas à manutenção da família, em especial as que vivem com baixos salários. A Argentina e o México têm vivenciado processos semelhantes de declínio da taxa de fecundidade, tendo atingido em 1998, respectivamente, 2,6 e 2,5 filhos por mulher em idade reprodutiva. (World Bank, 2000a).

A tendência declinante tanto da taxa de fecundidade como da taxa média geométrica de crescimento anual da população brasileira, no entanto, ainda está longe de representar um aumento populacional próximo de zero. O incremento populacional entre os anos de 1991 e 2000, em termos absolutos, representou mais de 22 milhões de pessoas no país, sendo que aproximadamente $42 \%$ deste incremento foi registrado na Região Sudeste. Região esta que se mantém como a mais urbanizada do país, o qual, por sua vez apresentou no ano 2000 uma taxa de urbanização próxima dos países centrais, de $81,23 \%$ (Tabela 1).

Tabela 1 - Brasil e Grandes Regiões. Crescimento populacional (1991-2000), taxa de urbanização e população total (2000).

\begin{tabular}{|c|c|c|c|c|c|}
\hline $\begin{array}{l}\text { Grandes } \\
\text { Regiões / }\end{array}$ & \multicolumn{2}{|c|}{$\begin{array}{l}\text { Taxa de crescimento } \\
\text { populacional }\left(\%^{\text {aa }}\right) *\end{array}$} & \multicolumn{2}{|c|}{$\begin{array}{c}\text { Taxa de urbanização } \\
(\%)\end{array}$} & $\begin{array}{l}\text { População } \\
\text { Total }\end{array}$ \\
\hline Brasil & $1980 / 91$ & $1991 / 00$ & 1980 & 2000 & 2000 \\
\hline Norte & 3,85 & 2,86 & 50,32 & 69,83 & 12893561 \\
\hline Nordeste & 1,83 & 1,30 & 50,46 & 69,04 & 47693253 \\
\hline Sudeste & 1,77 & 1,60 & 82,81 & 90,52 & 72297351 \\
\hline Sul & 1,38 & 1,42 & 62,41 & 80,94 & 25089783 \\
\hline Centro-Oeste & 3,01 & 2,37 & 70,84 & 86,73 & 11616745 \\
\hline Brasil & 1,93 & 1,63 & 67,59 & 81,23 & 169590693 \\
\hline
\end{tabular}

Fonte: FIBGE. Sinopse Preliminar do Censo Demográfico de 2000.

Nota: * taxa média geométrica de crescimento anual. 
O processo de urbanização, entendido como a transferência permanente de pessoas da área rural para a área urbana, praticamente já se consolidou na maioria dos países da América Latina. Segundo dados do Banco Mundial World Bank (2001), em 1999 a Argentina apresentava uma população urbana da ordem de $89 \%$ da população total e o México de $74 \%$, enquanto que a taxa de urbanização média dos países que constituem a região da América Latina e Caribe ${ }^{2}$ atingia $75 \% .^{3}$.

Outro fator relevante no que concerne à estrutura da população brasileira, e também da Argentina e México, é sua distribuição por faixas etárias, a qual apresenta, para as próximas décadas, taxa tendencial de crescimento negativo da população entre 0 e 14 anos e elevado crescimento para a população acima de 65 anos (Tabela 2). Para o caso brasileiro esta tendência é explicada pela "queda acumulada da fecundidade em mais de duas décadas, acrescida das alterações de padrões etários da mortalidade” (FIBGE, 2001: 21), ou seja, elevação da idade média da população brasileira e um menor número de filhos por família.

As implicações da reversão da taxa de crescimento por faixa etária é uma tendência relativamente recente no processo demográfico brasileiro e apresenta implicações importantes nas prospecções relacionadas ao mercado de trabalho. O indicador 'razão de dependência' calculado nas respectivas PNADs (FIBGE, 2001: 21) revela que "se em 1992 para cada 100 pessoas em idade ativa existiam 64 em idade não-ativa (crianças e idosos), em 1999, esta razão já havia declinado para 55 em cada 100”.

A síntese dos indicadores sociais elaboradas a partir da PNAD 1999 observa ainda que "a população de 30 a 59 anos de idade ainda crescerá razoavelmente, em termos absolutos, nas próximas décadas, embora em ritmo já bastante reduzido a partir da terceira década, ano 2020. Isto representará a continuidade durante este período de uma forte pressão demográfica sobre o

\footnotetext{
${ }^{2}$ Esta região compreende os seguintes países: Antigua e Barbuda, Argentina, Belize, Bolivia, Brasil, Chile, Colômbia, Costa Rica, Dominica, Equador, El Salvador, Granada, Guatemala, Guiana, Haiti, Honduras, Jamaica, México, Nicarágua, Organização dos Estados do Caribe Oriental (OECO), Panamá, Paraguai, Peru, República Dominicana, Saint Kitts e Nevis, San Vicente e Granadinas, Santa Lucía, Suriname, Trinidad e Tobago, Uruguai e República Bolivariana de Venezuela.

${ }^{3}$ População urbana para o Banco Mundial significa o percentual da população total que vive em áreas urbanas, as quais são definidas nos países de origem dos dados. No caso brasileiro, o perímetro urbano de um município é determinado por lei municipal.
} 
mercado de trabalho. Já os grupos de crianças, jovens e adultos jovens têm seus efetivos populacionais praticamente estabilizados a partir de 2005" (FIBGE, 2001: 22).

Tabela 2 - Países selecionados da América Latina. Dados populacionais.

\begin{tabular}{|c|c|c|c|c|c|c|c|c|}
\hline \multirow[t]{2}{*}{$\begin{array}{l}\text { Países / } \\
\text { Região }\end{array}$} & \multirow{2}{*}{$\begin{array}{l}\text { População } \\
\text { total } \\
\text { (milhões) } \\
1999\end{array}$} & \multicolumn{2}{|c|}{$\begin{array}{l}\text { \% da população } \\
\text { total em aglome- } \\
\text { rações urbanas } \\
\text { com mais de um } \\
\text { milhão de habi- } \\
\text { tantes }\end{array}$} & \multicolumn{2}{|c|}{$\begin{array}{l}\text { População na } \\
\text { maior metrópole } \\
\text { (\% da população } \\
\text { urbana) }\end{array}$} & \multicolumn{3}{|c|}{$\begin{array}{c}\text { Taxa média geométrica } \\
\text { anual de crescimento da } \\
\text { população } \\
(1999-2015) \\
\text { faixas etárias }\end{array}$} \\
\hline & & 1980 & 2000 & 1980 & 2000 & total & $0-14(\%)$ & $65+(\%)$ \\
\hline Argentina & 36,6 & 42 & 41 & 43 & 38 & 1,0 & $-0,1$ & 1,6 \\
\hline Brasil & 168,0 & 32 & 34 & 16 & 13 & 1,1 & 0,0 & 2,9 \\
\hline México & 96,6 & 28 & 28 & 31 & 25 & 1,3 & $-0,2$ & 3,2 \\
\hline $\begin{array}{l}\text { América La- } \\
\text { tina e Caribe }\end{array}$ & 508,2 & 29 & 32 & 27 & 25 & 1,3 & $-0,1$ & 2,8 \\
\hline
\end{tabular}

Fonte: World Bank (2001): World Development Indicators 2001 (Tabelas 1.5; 2.1; 3.10).

Uma maior nuclearização ${ }^{4}$ das unidades familiares foi igualmente constatada pela PNAD com um aumento de famílias unipessoais que passaram de 7,3\% a 8,6\% entre 1992 e 1999, o que significou um aumento relativo de $41 \%$ no período, "sendo que grande parte destas unidades são compostas por pessoas idosas" (FIBGE, 2001: 203). Este fato, não só confirma a tendência de envelhecimento da população brasileira, como gera uma demanda diferenciada por habitação e serviços públicos num futuro próximo, que deve ser devidamente acompanhada pelo poder público enquanto responsável pelo planejamento urbano e pela construção de equipamentos públicos.

\footnotetext{
${ }^{4}$ Nuclearização da família significa que parte de seus membros vive em habitações distintas.
} 


\section{Distribuição da população nos centros urbanos}

Os dados populacionais relativos ao Brasil, como também à Argentina e México, devem ser avaliados associados às informações relacionadas à distribuição populacional nos centros urbanos. É particularmente significativo os elevados indicadores representativos do percentual de população que reside nas aglomerações urbanas com mais de um milhão de habitantes e do percentual da população urbana nacional que habita a maior cidade em cada um destes países (Tabela 2).

A Argentina se diferencia do Brasil no que concerne ao percentual de população vivendo na maior metrópole, já que Buenos Aires, a capital do país, em 2000 concentrava 38\% da população urbana (Tabela 2). Córdoba e Rosário são as duas outras cidades que apresentavam em 2000 populações pouco superiores a 1 milhão de habitantes. Estas três cidades situam-se na parte central da Argentina, formando o principal corredor econômico do país, tanto agrário como industrial, o qual, em seus extremos unem a região do Rio da Prata ao Pacífico (Republica Argentina, 2001).

O México apresenta um padrão de distribuição geográfica da população similar ao da Argentina, já que a Região Metropolitana do México, a maior da América Latina, congrega 25\% da população urbana do país, pouco menos que os $28 \%$ que vivem em aglomerações com mais de 1 milhão de habitantes (Tabela 2). A maior parte da população mexicana vive em regiões próximas de onde se situa a capital, na área central do país, que corresponde a apenas 15\% da área territorial do país. Guadalajara é a segunda cidade mexicana quanto ao número de habitantes, com de 2,5 milhões em 2000, seguida de Monterrey que contava, na mesma data, com pouco mais de 2 milhões de pessoas. No entanto, nas últimas décadas tem se acentuado uma tendência migratória para a região fronteiriça com o sul dos Estados Unidos, devido a implantação de indústrias norte-americanas nesta região as "maquiadoras", devido ao baixo valor agregado regional que proporcionam já que à estas áreas se aplicam leis comerciais de 'zonas francas' 5 . Este processo fez com que as cidades fronteiriças de Ciudad Juarez, Mexicali e Tijuana apresentassem o maior crescimento populacional do país nas últimas décadas do século

\footnotetext{
${ }^{5}$ Entre essas leis a mais significativa relaciona-se à isenção de taxas de importação e exportação.
} 
XX, propiciando que estas três cidades atingissem no ano de 2000 populações ao redor de 1 milhão de habitantes (Migration News, 1999).

O Brasil distingue-se pela existência, em 2000, de 13 municípios com população acima de 1 milhão de habitantes, sendo que os 5 mais populosos, São Paulo, Rio de Janeiro, Salvador, Belo Horizonte e Fortaleza, além de estarem geograficamente distribuídos no território, concentram em conjunto apenas $13,6 \%$ da população total. São Paulo, o maior município brasileiro, detinha naquele ano $6,14 \%$ da população total do país, o que representava um contingente populacional de 10.405.867 pessoas (Tabela 3), sendo que a Região Metropolitana de São Paulo, na mesma data, seus 17.834 .664 habitantes significavam $10,5 \%$ do total do país.

Cabe notar que o padrão de distribuição espacial da população brasileira tem-se alterado após 1980, data na qual se constata o maior percentual de concentração populacional na Região Metropolitana de São Paulo $(10,6 \%)$ em relação ao total do país. Este percentual, que havia sido crescente desde a década de 1950, estabilizou-se em torno de 10,5\% a partir dos anos 80 . Comportamento semelhante tem sido apresentado pelo município de São Paulo, o qual tendo em 1980 concentrado 7,1\% da população do país, tem mantido percentuais em torno de 6,5\% desde então. Simultaneamente registra-se um maior crescimento das cidades médias, que são as definidas pelo FIBGE com população acima de 100.000 habitantes.

Este padrão de distribuição populacional tem se expandido para os demais estados brasileiros, tanto que a população residente nos municípios das capitais regionais do Brasil apresentaram entre 1991 e 2000, crescimento menor do que as regiões do interior de seus respectivos estados (Tabela 3). O conjunto das capitais estaduais não chegou a apresentar, nesta última década, redução significativa no percentual de população do total nacional, de $23,92 \%$ em 1991 para 23,82\% em 2000. Mas é significativo que a participação de população das capitais da Região Sudeste apesar de elevada, 46,50\% em 2000, vem declinando ao longo do tempo, cedendo importância às capitais das demais regiões (FIBGE, 2001a: 30).

O maior crescimento das cidades de porte médio no Brasil entre 1991 e 2000 foi constatado pelo censo demográfico de 2000. A avaliação divulgada pelo FIBGE (2001a) baseada 
nos dados preliminares destaca que "os municípios que perdem população estão compreendidos entre as faixas de 2.000 e 10.000 habitantes, [enquanto que os] na faixa de 10.000 a 100.000 habitantes, de um modo geral, apresentam baixo ou nenhum crescimento e aqueles que estão acima de 100 mil habitantes estão concentrados na faixa de 2,0\% a 3,0\% de crescimento anual" (FIBGE, 2001a: 25).

Caracteriza-se assim uma tendência de maior homogeneização da distribuição populacional no território brasileiro, revertendo a tendência de concentração nas maiores metrópoles que perdurou até fins dos anos 70. Isto se deve ao processo de diminuição de migração interna, quer pela maior consolidação de ocupação das fronteiras, quer pela menor concentração de atividades econômicas na Região Sudeste, particularmente na Região Metropolitana de São Paulo. Esta metrópole, que chegou a deter 42,2\% do total da produção industrial nacional em 1970, declinou sua participação no final do século XX para valores estimados abaixo de $25 \%{ }^{6}$.

Em termos de valores absolutos de população (Tabela 3), esta tendência de homogeneização deve ser contextualmente interpretada, já que efetivamente os municípios mais populosos do Brasil abrigam significativos contingentes populacionais, os quais continuam apresentando crescimento positivo, ainda que com taxas menores do que nos períodos anteriores. O incremento populacional do município de São Paulo entre 1991 e 2000, por exemplo, foi da ordem de 750 mil pessoas, o que evidentemente representa uma forte pressão sobre o mercado de trabalho e maior demanda de serviços públicos.

\section{Distribuição da renda e transformações no mercado de trabalho}

O início do século XXI apresenta desafios às economias latino-americanas, as quais, apesar de eventualmente favorecidas pelas diminuições das taxas de crescimento demográfico, tendem a um desenvolvimento dos indicadores econômicos e sociais ainda menor que o aumento

\footnotetext{
${ }^{6}$ Ver Schiffer (1999) quanto ao desempenho econômico e distribuição das atividades produtivas e população na Região Metropolitana de São Paulo no período 1980 a 2000.
} 
populacional ${ }^{7}$. Simultaneamente, as maiores aglomerações urbanas da região, seguindo um processo observado em décadas anteriores nas principais cidades mundiais, têm-se tornado predominantemente terciárias, particularmente com o crescimento do trabalho informal. Cacciamali (2001) ${ }^{8}$ calculou com base nos dados elaborados pela Organização Mundial do Trabalho (OIT) que entre 1990 e 1998 o Brasil e o México registraram incremento do percentual da força de trabalho no setor informal, respectivamente de 40,6\% para 47,5\% e de 38,4\% para 40,1\%. A Argentina, ao contrário apresentou percentual decrescente: 52,9\% em 1990 e 49,3\% em 1998, no entanto, registrou dentre os três países considerados (Tabela 4), a maior taxa de desemprego nos anos 1996/1998.

O Brasil observou igualmente um quadro de agravamento das taxas de desemprego a partir dos anos 1980. México e Brasil identificam-se também por uma distribuição de renda bastante desigual (Tabela 4). No Brasil, que particularmente apresenta uma das piores distribuições de renda entre os países avaliados pelo Banco Mundial ${ }^{9}$, a distribuição de renda tem mantido-se inalterada nas últimas décadas, demonstrando que os planos econômicos aplicados desde fins dos anos 70 não têm favorecido as populações de baixa renda.

\footnotetext{
${ }^{7}$ Ver World Bank Development Report 2000/01.

${ }^{8}$ Texto elaborado no âmbito desta pesquisa Capes/Cofecub, intitulado preliminarmente "Processo de informalidade, flexibilização das relações de trabalho e proteção social na América Latina. Perdas da contribuição à seguridade social no Brasil".

${ }^{9}$ Conforme tabela 2.4 do "World Bank, 2001 World Development Indicators".
} 
Tabela 3 - Brasil, regiões metropolitanas e municípios mais populosos. Dados populacionais (1991-2000).

\begin{tabular}{|c|c|c|c|c|c|}
\hline \multirow{2}{*}{$\begin{array}{c}\text { Regiões Metropolitanas, } \\
\text { RIDE (1) e Municípios mais } \\
\text { populosos }\end{array}$} & \multicolumn{2}{|c|}{ População residente em } & \multirow{2}{*}{$\begin{array}{c}\text { crescimento } \\
\text { populacional } \\
\text { aboluto } \\
1991 / 2000\end{array}$} & \multirow{2}{*}{$\begin{array}{l}\text { Taxa geomé- } \\
\text { trica de cresci- } \\
\text { mento anual } \\
1991 / 2000\end{array}$} & \multirow{2}{*}{$\begin{array}{c}\text { Densidade } \\
\text { demográfica } \\
(\mathrm{hab} / \mathrm{km} 2)\end{array}$} \\
\hline & $\begin{array}{l}1991 \\
\text { Total }\end{array}$ & $\begin{array}{l}2000 \\
\text { Total }\end{array}$ & & & \\
\hline Belém..... & 1491305 & 1794981 & 303676 & 2,08 & 986,52 \\
\hline Belém & 1080692 & 1279861 & 199169 & 1,92 & 1201,39 \\
\hline Fortaleza.. & 2307017 & 2975703 & 668686 & 2,87 & 600,67 \\
\hline Fortaleza & 1768637 & 2138234 & 369597 & 2,15 & 6844,94 \\
\hline Recife.... & 2919979 & 3335704 & 415725 & 1,49 & 1216,21 \\
\hline Recife. & 1298229 & 1421993 & 123764 & 1,03 & 6529,43 \\
\hline Salvador........... & 2496521 & 3018285 & 521764 & 2,13 & 1290,07 \\
\hline Salvador. & 2075273 & 2440828 & 365555 & 1,84 & 7521,08 \\
\hline Belo Horizonte............... & 3436060 & 4811760 & 1375700 & 3,81 & 333,76 \\
\hline Belo Horizonte. & 2020161 & 2232747 & 212586 & 1,13 & 6746,79 \\
\hline Rio de Janeiro................................... & 9814574 & 10872768 & 1058194 & 1,14 & 1899,46 \\
\hline Nova Iguaçu.. & 772399 & 915366 & 142967 & 1,92 & 1640,40 \\
\hline Rio de Janeiro... & 5480768 & 5851914 & 371146 & 0,74 & 4640,37 \\
\hline 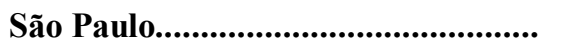 & 15444941 & 17834664 & 2389723 & 1,61 & 2245,13 \\
\hline Guarulhos.. & 787866 & 1071268 & 283402 & 3,51 & 3378,27 \\
\hline São Paulo.... & 9646185 & 10405867 & 759682 & 0,85 & 6823,68 \\
\hline 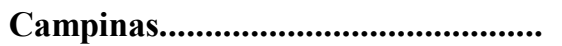 & $\ldots$ & 2333230 & $\ldots$ & $\ldots$ & 640,00 \\
\hline Campinas.... & 847595 & 968172 & 120577 & 1,50 & 1216,77 \\
\hline Curitiba.................... & 2057578 & 2725629 & 668051 & 3,17 & 204,54 \\
\hline Curitiba. & 1315035 & 1586848 & 271813 & 2,13 & 3690,23 \\
\hline Porto Alegre....... & 3027848 & 3655834 & 627986 & 2,12 & 445,17 \\
\hline Porto Alegre.... & 1251885 & 1360033 & 108148 & 0,93 & 2744,58 \\
\hline Goiânia................................................... & ... & 1636465 & ... & ... & 410,05 \\
\hline 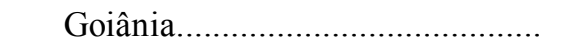 & 920640 & 1090737 & 170097 & 1,92 & 1472,96 \\
\hline $\begin{array}{l}\text { Região Integrada de Desenvolviment } \\
\text { do Distrito Federal e Entorno........... }\end{array}$ & .. & 2943420 & $\ldots$ & $\ldots$ & 53,15 \\
\hline Brasília (DF).............................. & 1601094 & 2043169 & 442075 & 2,77 & 352,16 \\
\hline Manaus... & 1011501 & 1403796 & 392295 & 3,74 & $\ldots$ \\
\hline BRASIL & 146825475 & 169590693 & 22765218 & 1,63 & \\
\hline
\end{tabular}

Nota: ... sem informação.

Fontes: elaborado a partir de: FIBGE, Sinopse Preliminar do Censo Demográfico 2000 (Tabela 3.2) e EMPLASA (1997). (1) A RIDE (Região Integrada de Desenvolvimento do Distrito Federal e Entorno) é composta por municípios das Unidades da Federação de Minas Gerais, Goiás e Distrito Federal.

(2) Exclusive a população residente nas áreas urbanas isoladas.

(3) Valores incluindo as águas interiores.

(4) Valores sujeitos a alteração em face de atualizações de natureza cartográfica ou político-administrativa. 
O diagnóstico elaborado a partir das PNADs de 1992 e 1999 igualmente expressa uma piora das desigualdades de renda internamente ao Brasil. "Quando se analisa o rendimento médio dos 10\% mais ricos da distribuição da renda (medidos em salários mínimos) verifica-se um crescimento substancial no período, passando de 13,33 salários mínimos a 18,44 salários mínimos, enquanto, aqueles que se encontram nos $40 \%$ mais pobres, não chegaram ultrapassar sequer 1 salário mínimo de rendimento médio (0,98 salário mínimo), em 1999, embora em 1992, tivessem apenas 0,70 salário mínimo. Essa desigualdade em nível regional é bastante significativa, principalmente, quando se observa os dados da Região Nordeste para 1999, que apresentou, mesmo tendo alcançado uma ligeira melhoria no período, o menor rendimento médio dos 40\% mais pobres, 0,61 salário mínimo. O Sudeste continua a apresentar o maior, 1,35 salários mínimos" (FIBGE, 2001: 116-117).

Tabela 4 - Países selecionados da América Latina. Dados sócio-econômicos.

\begin{tabular}{|c|c|c|c|c|c|c|c|c|c|c|c|}
\hline \multirow{3}{*}{$\begin{array}{l}\text { países/ } \\
\text { região } \\
\text { Argentina }\end{array}$} & \multirow{2}{*}{\multicolumn{2}{|c|}{$\begin{array}{l}\text { Produto Nacional } \\
\text { Bruto (PNB) } \\
\text { (US\$ milhões) } \\
1990 \quad 1999\end{array}$}} & \multirow{2}{*}{\multicolumn{2}{|c|}{$\begin{array}{l}\text { Valor adi- } \\
\text { cionado } \\
\text { industrial } \\
\text { ( \% PNB) } \\
19901999\end{array}$}} & \multicolumn{2}{|c|}{$\begin{array}{l}\text { Valor } \\
\text { adicionado } \\
\text { serviços } \\
(\% \text { PNB) }\end{array}$} & \multirow{2}{*}{\multicolumn{2}{|c|}{$\begin{array}{l}\text { Taxa de } \\
\text { desemprego } \\
\text { total } \\
(\% \text { da força de } \\
\text { trabalho) } \\
1980 / 82 \\
1996 / 98\end{array}$}} & \multirow{2}{*}{\multicolumn{2}{|c|}{$\begin{array}{l}\text { Distribuição da } \\
\text { renda } \\
\text { (particip. na ren- } \\
\text { da nacional) * } \\
40 \%-\quad 10 \%{ }^{+}\end{array}$}} & \multirow{3}{*}{$\begin{array}{l}\text { PNB } \\
\text { per } \\
\text { capita } \\
\text { (US\$) } \\
1999 \\
7.550\end{array}$} \\
\hline & & & & & \multicolumn{2}{|c|}{19901999} & & & & & \\
\hline & 141.352 & 283.166 & 27 & 18 & 56 & 67 & 2,3 & 16,3 & .. & .. & \\
\hline Brasil & 464.989 & 751.505 & 25 & 23 & 53 & 61 & 2,8 & 7,8 & (2) 5,7 & 46,7 & 4.350 \\
\hline México & 262.710 & 483.737 & 21 & 21 & 64 & 67 & .. & 2,3 & (1) 7,6 & 41,1 & 4.440 \\
\hline $\begin{array}{l}\text { América } \\
\text { Latina e } \\
\text { Caribe }\end{array}$ & 1.136 .103 & 2.052 .720 & 24 & 21 & 55 & 62 & .. & .. & .. & .. & 3.800 \\
\hline
\end{tabular}

Fonte: World Bank (2001): World Development Indicators 2001 (Tabelas 1.1; 2.4; 2.8; 4.2).

Notas: Sem informação.

* Referente aos anos (1) 1996; (2) 1997. 
No que se refere à renda familiar, estes mesmos levantamentos registraram que "enquanto a renda média familiar per capita das famílias que estão nos $10 \%$ mais ricos da distribuição de renda ficou em torno de 11 salários mínimos, em 1999, aquela verificada para as famílias que estão nos 40\% mais pobres é de apenas 0,5 salário mínimo. Esse valor praticamente não oscilou durante o período compreendido entre 1992 e 1999, comportamento diverso daquele observado para o rendimento dos $10 \%$, que oscilou com tendência de crescimento. A diferença entre os rendimentos destes dois extratos é muito grande - os $10 \%$ mais ricos têm um rendimento 22 vezes maior que o dos 40\% mais pobres" (FIBGE, 2001: 117).

A extrema desigualdade das rendas familiares entre os mais ricos e os mais pobres da população brasileira é ainda mais preocupante quando se analisa esse dado em função da média de pessoas e de filhos nas famílias. Apesar de uma redução generalizada dos números médio de pessoas por família que vem ocorrendo nas últimas décadas, as PNDs 1992 e 1999 indicam a manutenção neste período da tendência de quanto menor a renda familiar maior o número de pessoas e filhos, conforme distribuição percentual apresentada para o ano de 1998 (Tabela 5).

Esta constatação indica estar havendo um maior adensamento populacional nas áreas aonde se aloca predominantemente a população de baixa renda. Esta tendência é significativa no que se refere à distribuição de infra-estrutura urbana, pois a população de menor renda já convive com escassos equipamentos de educação, habitação e saneamento básico, como discutido adiante. 
A população de menor renda e escolaridade, tanto no Brasil quanto nos demais países latino-americanos também têm sofrido com maior intensidade os fatores negativos decorrentes das transformações recentes no mercado de trabalho. Tais transformações, correntemente atribuídas à intensificação de globalização da economia ${ }^{10}$, tem afetado velozmente os processos produtivos que se tem tornado cada vez mais intensivos de capital e orientados para a força de trabalho com maior qualificação.

Tabela 5 - Número médio de filhos, na família, residentes em domicílios particulare respectiva distribuição percentual, por classes de renda familiar per capita em salári mínimos, segundo as Grandes Regiões e Regiões Metropolitanas - 1998.

\begin{tabular}{|c|c|c|c|c|c|c|c|c|}
\hline \multirow{3}{*}{$\begin{array}{l}\text { Grandes Regiões, } \\
\text { Unidades da Federação e } \\
\text { Regiões Metropolitanas }\end{array}$} & \multicolumn{8}{|c|}{ Número médio de filhos, na família, residentes em domicílios particulares } \\
\hline & \multirow[b]{2}{*}{$\begin{array}{c}\text { Total } \\
\text { (1) }\end{array}$} & \multicolumn{7}{|c|}{ Classes de renda familiar per capita em salários mínimos (\%) } \\
\hline & & Até $1 / 4$ & $\begin{array}{c}\text { Mais de } \\
1 / 4 \text { até } \\
1 / 2\end{array}$ & $\begin{array}{l}\text { Mais de } \\
1 / 2 \text { até } 1\end{array}$ & $\begin{array}{c}\text { Mais de } \\
1 \text { a } 2\end{array}$ & $\begin{array}{c}\text { Mais de } \\
2 \text { a } 3\end{array}$ & $\begin{array}{c}\text { Mais de } \\
3 \text { a } 5\end{array}$ & $\begin{array}{c}\text { Mais de } \\
5\end{array}$ \\
\hline Brasil (2) & 1,6 & 3,3 & 2,4 & 1,8 & 1,3 & 1,2 & 1,2 & 0,9 \\
\hline Norte (3) & 2,0 & 3,5 & 2,7 & 2,0 & 1,6 & 1,5 & 1,4 & 1,1 \\
\hline Reg. Metrop. de Belém & 1,6 & 3,0 & 2,3 & 1,8 & 1,4 & 1,3 & 1,3 & 1,1 \\
\hline Nordeste & 1,9 & 3,4 & 2,4 & 1,6 & 1,0 & 1,2 & 1,2 & 1,1 \\
\hline Reg. Metrop. de Fortal & 1,7 & 3,2 & 2,5 & 1,8 & 1,3 & 1,1 & 1,3 & 1,1 \\
\hline Reg. Metrop. de Recif & 1,6 & 2,9 & 2,2 & 1,6 & 1,2 & 1,4 & 1,2 & 1,0 \\
\hline Reg. Metrop. de Salvador & 1,6 & 3,0 & 2,4 & 1,8 & 1,4 & 1,2 & 1,2 & 1,0 \\
\hline Sudeste & 1,5 & 3,3 & 2,5 & 1,9 & 1,4 & 1,3 & 1,2 & 0,9 \\
\hline Reg. Metrop. de Belo Horizo & 1,7 & 3,2 & 2,7 & 2,1 & 1,5 & 1,4 & 1,1 & 1,0 \\
\hline Reg. Metrop. do Rio de Janeiro & 1,2 & 2,9 & 2,2 & 1,7 & 1,3 & 1,0 & 0,9 & 0,7 \\
\hline Reg. Metrop.de São Paulo & 1,5 & 3,4 & 2,8 & 2,1 & 1,6 & 1,3 & 1,2 & 1,0 \\
\hline Sul & 1,4 & 2,9 & 2,3 & 1,7 & 1,2 & 1,1 & 1,1 & 0,9 \\
\hline Reg. Metrop. $c$ & 1,4 & 3,0 & 2,4 & 1,9 & 1,4 & 1,2 & 1,1 & 0,9 \\
\hline Reg. Metrop. de Porto Alegre & 1,3 & 2,9 & 2,7 & 1,9 & 1,3 & 1,1 & 1,0 & 0,7 \\
\hline Centro-Oeste & 1,5 & 3,0 & 2,3 & 1,7 & 1,3 & 1,2 & 1,2 & 1,1 \\
\hline
\end{tabular}

Fonte: elaborado a partir da Pesquisa nacional por amostra de domicílios 1998 [CD-ROM]. Microdados.

Rio de Janeiro: IBGE, 1999, (Tabela 6.10).

Notas: 1. Exclusive as pessoas cuja condição na família era pensionista, empregado doméstico e parente do empregado doméstico.

2. Os valores da renda do ano de 1998 foram inflacionados pelo INPC com base em setembro de 1999 e expressos em salários mínimos de 1999.

(1) Inclusive as famílias sem declaração e sem rendimento, (2) Exclusive a população rural de Rondônia, Acre, Amazonas, Roraima, Pará e Amapá, (3) Exclusive a população rural.

\footnotetext{
${ }^{10}$ Estas transformações encontram-se discutidas com maior profundidade nos textos específicos que fazem parte desta pesquisa CAPES/Cofecub.
} 
As metrópoles da América Latina que há pouco mais de uma década eram predominantemente dependentes do setor secundário, quer quanto ao valor da produção como quanto aos níveis de emprego, têm-se tornado predominantemente terciárias, seguindo as tendências nacionais (Tabela 4). Tomando-se a Região Metropolitana de São Paulo como exemplo, os dados da Pesquisa do Emprego e Desemprego - PED - (SEADE, 2001), indicam que para o total da população em idade ativa ${ }^{11}$, para os anos de 1985, 1992 e 2000, respectivamente, o percentual de ocupados era $53,0 \%, 52,1 \%$ e $51,5 \%$, sendo que no setor industrial este percentual era de $17,4 \%, 13,8 \%$ e 10,2\%. Nas mesmas datas o setor de serviços registrou um crescimento relativo de ocupados de $21,6 \%, 24,0 \%$ e $27,3 \%$ do total da população ativa (SEADE, 2001). Nos valores relativos ao setor serviços encontram-se contabilizados grande parte dos ocupados no setor informal, conforme avaliado por Cacciamali (1995). Além disso, os valores relativos às parcelas da força de trabalho vinculadas aos setores "indústria" e "serviços" devem ser analisados com cautela face à expansão do processo de terceirização das atividades econômicas, em particular no setor industrial, não detectadas nas estatísticas oficiais de emprego.

\section{Distribuição dos serviços básicos e evolução dos indicadores sociais.}

O crescimento populacional positivo nas principais cidades do Brasil, México e Argentina, aliado ao aumento de desemprego, em especial para os menos qualificados, e uma tendência de baixo crescimento econômicos nestas nações, geram uma crescente pressão não só no mercado de trabalho, mas também sobre os serviços urbanos, particularmente, habitação, educação e saneamento.

As conseqüências da desigualdade inter-pessoal de renda, apontadas no item anterior, se refletem igualmente na distribuição dos serviços públicos, já que as metrópoles latino-americanas aqui consideradas apresentam um padrão de ocupação espacial na qual as periferias são basicamente ocupadas de forma bastante precária, sem infra-estrutura adequada e a maioria das habitações construídas em padrão sub-normal, por população de baixa renda. Novamente

\footnotetext{
${ }^{11}$ População em idade ativa (PIA) refere-se à parcela da população com idade igual ou superior a 10 anos, conforme conceito definido pela Pesquisa Emprego e Desemprego -PED - da Fundação SEADE.
} 
encontra-se nas PNADs, para o caso brasileiro, a confirmação da extrema segregação espacial urbana, fruto da desigualdade de renda. "Nos 10\% mais ricos, cerca de 80,1\% de domicílios tinham saneamento básico adequado enquanto nos $40 \%$ mais pobres a proporção era de apenas 32,3\%" (FIBGE, 2001: 116).

A adequação das habitações em termos de infra-estrutura pode ser avaliada a partir de três indicadores básicos: abastecimento de água conectado à rede geral com canalização interna, esgotamento sanitário ligado à rede geral ou fossa séptica e percentual de lixo coletado. Apesar das PNADS 1992 e 1999 mensurarem que, a nível nacional, houve um incremento no respectivo período, de 53,8\% para $62,3 \%$, no total de domicílios que eram atendidos por estas três infraestruturas, a população de menor renda continua vivenciando enorme precariedade nesses serviços, conforme dados apresentados para 1998 (Tabela 6). "Entre os domicílios pobres (com renda per capita de até $1 / 2$ salário mínimo) apenas 34,1\% tinham um saneamento adequado embora tenha havido uma pequena melhora em relação a 1992, quando esse percentual era de 27\%. Para as classes de maiores rendimentos a situação permaneceu quase inalterada" (FIBGE, 2001: 178).

O grau de instrução representa um fator preponderante quanto às oportunidades no mercado de trabalho, o que, em última instância afeta o nível de renda familiar e conseqüentemente as condições de vida decorrentes. Para o conjunto das regiões brasileiras os dados das PNADs 1992 e 1999 indicam que "a taxa de atividade por anos de estudo cresce à medida que aumenta a escolaridade, ou seja, quanto maior for o grau de instrução maiores seriam as facilidades médias para se encontrar uma vaga no mercado de trabalho".

No período em questão, os grupos com menor escolaridade apresentaram uma redução maior que os grupos mais instruídos" (FIBGE, 2001: 115). Mesmo com esta redução as desigualdades de educação em função da renda familiar ainda permanecem elevadas, já que "o percentual de estudantes de nível superior é muito desigual: nos 10\% mais ricos, verificou-se um percentual de $21,0 \%$ dos estudantes de nível superior de 20 a 24 anos, enquanto nos $40 \%$ mais pobres essa proporção era insignificante, 2,6\%" (FIBGE, 2001: 116). 
Tabela 6 - Domicílios particulares permanentes urbanos, total e percentagem dos dor abastecimento de água e esgotamento sanitário adequado e lixo coletado, por classes renda domiciliar per capita em salários minímos, segundo as Grandes Regiões e Regiões Metropolitanas - 1998.

\begin{tabular}{|c|c|c|c|c|c|c|c|c|}
\hline \multirow{4}{*}{$\begin{array}{c}\text { Grandes Regiões, } \\
\text { Unidades da Federação e } \\
\text { Regiões Metropolitanas }\end{array}$} & \multicolumn{8}{|c|}{ Domicílios particulares permantes urbanos } \\
\hline & \multirow[t]{3}{*}{ Total } & \multicolumn{7}{|c|}{ Com abastecimento de água e esgotamento sanitário adequado e lixo coletado } \\
\hline & & \multirow{2}{*}{$\begin{array}{c}\text { Total } \\
(\%)\end{array}$} & \multicolumn{6}{|c|}{ Classes de renda domiciliar per capita em salarios minímos (\%) } \\
\hline & & & Até $1 / 2$ & $\begin{array}{c}\text { Mais de } \\
1 / 2 \text { a } 1\end{array}$ & $\begin{array}{c}\text { Mais de } \\
1 \text { a } 2\end{array}$ & $\begin{array}{c}\text { Mais de } \\
2 \text { a } 3\end{array}$ & $\begin{array}{c}\text { Mais de } \\
3 \text { a } 5\end{array}$ & $\begin{array}{c}\text { Mais de } \\
5\end{array}$ \\
\hline Bra & 33993829 & 61.8 & 31.7 & 48.7 & 64.6 & 74.1 & 80.0 & 86.0 \\
\hline Nort & & 14.2 & 7.2 & 9.1 & 14.2 & 25.4 & 23.5 & 35.9 \\
\hline Reg. Metro & & 34.9 & 19.2 & 27.9 & & 43.1 & 47.0 & 64 \\
\hline & 719 & 31.0 & & & & 44.1 & .7 & 62.8 \\
\hline Reg. Metr & & 29.8 & 20.2 & 2 & 31 & 29.6 & 44.8 & 61.6 \\
\hline Reg. Metr & 748 & 41.7 & 24.6 & 33.2 & 41 & 58.5 & 71.3 & 80.1 \\
\hline Reg. Metrop. de & 69 & 66.0 & 48.2 & 58.1 & 63.4 & 76.6 & 80.9 & 90.4 \\
\hline Sudeste & 17206702 & 85.1 & 63.2 & 76.1 & & 90.3 & .0 & 96.3 \\
\hline Metr & & 84.6 & & & & 85 & & 98. \\
\hline Reg. Metrc & & 80.9 & 59.5 & & 77 & 84 & .3 & 96.3 \\
\hline Reg. Metrop. de São Paulo & 461 & 90.5 & 78.9 & 79.8 & 88 & 94.0 & 95.0 & 97. \\
\hline Sul & 5482600 & 53.0 & 27.7 & 37. & 48 & 60.1 & 71.5 & 76 \\
\hline Metro & & 69.4 & 50.9 & & & 68.4 & 84.9 & 89 \\
\hline Reg. Metrc & & 83.1 & 62.3 & 74.5 & 79.8 & 86.5 & 90.7 & 92.0 \\
\hline Centro-Oeste & 2443014 & 41.0 & 21.9 & 28.6 & 38.4 & 48.0 & 58.5 & 73.1 \\
\hline
\end{tabular}

Fonte: elaborado a partir da Pesquisa nacional por amostra de domicílios 1998 [CD-ROM]. Microdados.

Rio de Janeiro: IBGE, 1999. (Tabela 5.10)

Nota: Os valores da renda do ano de 1998 foram inflacionados pelo INPC com base em setembro de 1999 e expressos em salários mínimos de 1999.

(1) Inclusive os sem declaração e sem rendimento.

Se, por um lado, tanto a distribuição dos serviços públicos básicos como a evolução dos indicadores sócio-econômicos no Brasil não registraram melhora significativa desde os anos de 1980, por outro lado, importantes transformações ocorreram no período quanto aos processos produtivos industriais e no desenvolvimento de atividades econômicas avançadas, em especial, no setor financeiro vinculado à economia global. A maior intensificação de capital no setor industrial não só reduziu drasticamente o número de empregos no setor como modificou a distribuição espacial das plantas industriais, acelerando o processo de desconcentração industrial 
das grandes metrópoles, particularmente na Região Metropolitana de São Paulo, no caso brasileiro $^{12}$.

A transferência de plantas industriais obsoletas para novas áreas externas à Região Metropolitana de São Paulo legou aos municípios atingidos grandes áreas construídas e vazias, muitas das quais degradadas, mas situadas em zonas próximas aos centros históricos e dotadas de infra-estrutura básica. A gestão pública destas cidades, na perspectiva de menores taxas de crescimento demográfico e na manutenção do quadro sócio-econômico exposto acima, deveria incorporar novas ações e planos voltados à renovação urbana destas áreas, objetivando melhorar a qualidade de vida da população de baixa renda ${ }^{13}$. A perspectiva de investimentos na conservação e renovação do patrimônio construído não só representa alternativas de trabalho para a população menos qualificada como pode se constituir em importante instrumento de inclusão social na medida que incorpora valores culturais e históricos ao processo de desenvolvimento urbano $^{14}$.

Os investimentos em conservação do patrimônio construído, particularmente o histórico e/ou cultural, tem sido reconhecidos pelos bancos de desenvolvimento internacional, em especial o Banco Mundial e o Banco Interamericano de Desenvolvimento -BIRD-, como importante fator na redução dos níveis de pobreza. Vários projetos-piloto tem sido implementados por estes órgãos ${ }^{15}$, além da formação de grupos de estudos ${ }^{16}$ com participação de pesquisadores externos, visando gerar programas de financiamento, e/ou empréstimos "a fundo perdido", em projetos de conservação ou renovação urbana que tenham impacto no alívio dos índices de pobreza local. $\mathrm{O}$ engajamento das gestões municipais nestes programas pode se constituir em fonte alternativa de recursos orientados a ampliar as oportunidades no mercado de trabalho ${ }^{17}$, obviamente tendo-se

\footnotetext{
${ }^{12}$ Ver Schiffer (2002) sobre evolução da forma urbana da metrópole paulista e desenvolvimento econômico.

${ }^{13}$ Ver Schiffer (2001) para maiores detalhes sobre relações entre conservação do patrimônio urbano, inclusão social e qualidade de vida urbana.

${ }^{14}$ Ver Cardia e Schiffer (2000) sobre relações entre qualidade de vida urbana, níveis de pobreza e violência.

15 Os resultados relativos aos projetos-piloto implementados na Ásia e África encontram-se avaliados em IRBD/World Bank (2001).

${ }^{16}$ Ver World Bank web sites relacionados a Cultura (www.worldbank.org/culture) e PovertyNet (www.worldbank.org/poverty).

${ }^{17}$ Ver Zancheti (1998) sobre avaliação dos impactos socioeconômicos resultantes da intervenção na recuperação de área histórica de Recife.
} 
em conta as limitações impostas a esse mercado pelos fatores estruturais macro-econômicos nacionais.

\section{Considerações finais}

Os países latino-americanos, em especial, Brasil, Argentina e México, têm como maior desafio neste início de século XXI implementar políticas públicas direcionadas a uma significativa melhora da distribuição inter-pessoal de renda e na redução sensível do número de famílias vivendo em condições habitacionais inadequadas. Tais políticas, para serem efetivas, devem orientar-se não somente ao provimento dos serviços básicos a toda sorte de domicílios urbanos, como também essencialmente prever uma reestruturação do mercado de trabalho gerando oportunidades alternativas de emprego para aqueles com menor qualificação, não inseridas nas atividades econômicas avançadas que tem se generalizado na maior parte dos setores em expansão.

As perspectivas de menor crescimento populacional, especialmente nas metrópoles, bem como dos índices dos indicadores macro-econômicos dos países latino-americanos como o Brasil, Argentina e México, implicam também em uma revisão das políticas urbanas para os próximos anos. O crescente processo de terciarização dessas metrópoles, bem como os altos índices de pobreza urbana, incitam a incluir nas propostas de planejamento urbano /regional a renovação de áreas urbanas, previamente ocupadas por indústrias, cujos edifícios encontram-se muitas vezes degradados ou vazios, mas localizados em áreas com infra-estrutura básica já implementada.

O foco destas políticas urbanas, bem como das demais políticas públicas, deveria ser a população de baixa renda, já que esta tende a ser cada vez mais excluídas do processo atual de internacionalização da economia, portanto sua inclusão social torna-se mais do que nunca dependente de políticas compensatórias e ações específicas por parte dos governos nacionais e locais. 


\section{Referências bibliográficas}

CACCIAMALI, M. C. Mercado de trabalho no Brasil e na década de 1990: menos empregos, mais política pública. In: VELLOSO, J.P.R. (org.) O real e o futuro da economia. Rio e Janeiro: José Olympio, 1995, p.213-231.

CARDIA, N. \& SCHIFFER, S. São Paulo Secondary Data Analysis. In: WHO Project in Urbanization, Youth and Risk Factors for Substance Abuses. Geneva: WHO. 2000. (mimeo)

EMPLASA - Empresa Metropolitana de Planejamento da Grande São Paulo S.A. Sumário de dados da Grande São Paulo. São Paulo: Secretaria de Estado de Planejamento e Gestão, vários anos.

FIBGE - Fundação Instituto Brasileiro de Geografia e Estatística. Pesquisa Nacional de Amostra Domiciliar - PNAD. Rio de Janeiro: IBGE, vários anos.

FIBGE - Fundação Instituto Brasileiro de Geografia e Estatística. Sinopse preliminar do censo demográfico de 2000. Rio de Janeiro: IBGE, 2001.

FIBGE - Fundação Instituto Brasileiro de Geografia e Estatística. Síntese dos indicadores socais 2000. Rio de Janeiro: IBGE, 2001. (Estudos \& Pesquisas 5. Informações demográficas e sócio-econômicas.) CD-ROM.

FSEADE - Fundação Sistema Estadual de Análise de Dados. Anuário estatístico do Estado de São Paulo. São Paulo: SEADE, 2001. (web site www.seade.gov.br) (Coletânea de Tabelas)

FSEADE - Fundação Sistema Estadual de Análise de Dados. Pesquisa do Emprego e do Desemprego (PED). São Paulo: SEADE, vários anos.

FIBGE - Fundação Instituto Brasileiro de Geografia e Estatística. Censos. Rio de Janeiro: IBGE, vários anos. 
IRBD/World Bank . Cultural Heritage and development. A framework for action in the Middle East and North Africa. Washington: The Word Bank, 2001. (Orientations in Development Series).

Migration News (1999). Mexico: demography, remittances. Vol. 6, N. 7. (web site http://migration.ucdavis.edu/mn, setembro 2001).

Republica Argentina. Secretaria de Cultura de la Naciòn. The immigrants arrival II. (web site www.surdelsur.com/tierra), setembro 2001.

SCHIFFER, S. R. São Paulo: Globalização da economia e impactos urbanos. In: RIGATTI, D. (org.) Anais do VIII Encontro Nacional da ANPUR. Porto Alegre: ANPUR/PROPUR/UFRGS, 1999. (CD-Rom)

SCHIFFER, S. R. Rethinking Urban Form and Development in Latin America. In: Carmona, M. et alli. Globalization, Form and Governance (5). Delft: Delft University of Technology, 2001, p. 27-36.

SCHIFFER, S. R.. Economic restructuring and urban segregation in São Paulo. In: MARCUSE, P. \& VAN KEMPEN, R. (org.). Of States and Cities. Londres: Oxford University Press, 2002, p. 143-169.

World Bank . World Development Report 2000/01. Washington: The World Bank, 2000.

World Bank . World Development Indicators 2000. Washington: The World Bank, 2000.

World Bank . World Development Indicators 2001. Washington: The Word Bank. (web site www.worldbank.org/wdr, setembro 2001).

ZANCHETI, S.M. et al. (orgs.). Revitalização do Bairro do Recife: plano, regulação e avaliação. Recife: CECI/UFPE, 1998. 